\title{
Full scope of practice
}

As A PHARMACIST WORKING WITHIN A PRIMARY CARE TEAM, I am fortunate to practise in a manner not dissimilar to the model outlined by Gobis and colleagues in their recent article, "The UBC Pharmacists Clinic: A Catalyst for Practice Change." Let me state that there are few things more gratifying than practising to the full scope of my potential and effecting positive patient outcomes.

Make no mistake, though: being a pharmacotherapy specialist collaborating with other patient care providers is a move to the major leagues for many pharmacists. Such a transition requires courage and commitment-courage to venture outside the comfort zone to exceed the standards of care, and commitment to acquire the skills necessary to adopt an evidence-based, patient-centred approach.
For their part, the professional organizations, including the Canadian Pharmacists Association, should receive credit for providing educational tools to aid pharmacists in expanding their scope. While some may point out that the lack of infrastructure remains a barrier for pharmacists to optimize their clinical time, no one should claim that continuing education resources are unavailable to help pharmacists engage in advanced levels of practice.

- Thuan Nguyen, BScPhm, CDE, CGP

Toronto, $\mathrm{ON}$

\section{Reference}

1. Gobis B, Leung L, Min J, et al. The UBC Pharmacists Clinic: a catalyst for practice change. Can Pharm J (Ott) 2016;149:9-12. 